\title{
Responsiveness of voltage-gated calcium channels in SH-SY5Y human neuroblastoma cells on quasi-three-dimensional micropatterns formed with poly (I-lactic acid)
}

\author{
This article was published in the following Dove Press journal: \\ International Journal of Nanomedicine \\ 31 December 2012 \\ Number of times this article has been viewed
}

\section{Ze-Zhi Wu' \\ Zheng-Wei Wang' \\ Li-Guang Zhang' \\ Zhi-Xing An' \\ Dong-Huo Zhong' \\ Qi-Ping Huang' \\ Mei-Rong Luo' \\ Yan-Jian Liao' \\ Liang Jin' \\ Chen-Zhong $\mathrm{Li}^{2}$ \\ William S Kisaalita ${ }^{3}$ \\ 'Key Laboratory of Biorheological Science and Technology of the State Ministry of Education, College of Bioengineering, Chongqing University, Chongqing, People's Republic of China; ${ }^{2}$ Nanobioengineering/Bioelectronics Laboratory, Department of Biomedical Engineering, Florida International University, Miami, Florida, ${ }^{3}$ Cellular Bioengineering Laboratory, College of Engineering, University of Georgia, Athens, Georgia, USA}

Correspondence: Ze-Zhi Wu

Key Laboratory of Biorheological Science and Technology of the State Ministry of Education, College of Bioengineering, Chongqing University, Chongqing 400044, People's Republic of China $\mathrm{Tel} / \mathrm{Fax}+862365102507$

Email zzwu@cqu.edu.cn
Introduction: In this study, quasi-three-dimensional (3D) microwell patterns were fabricated with poly (1-lactic acid) for the development of cell-based assays, targeting voltage-gated calcium channels (VGCCs).

Methods and materials: SH-SY5Y human neuroblastoma cells were interfaced with the microwell patterns and found to grow as two dimensional (2D), 3D, and near two dimensional (N2D), categorized on the basis of the cells' location in the pattern. The capability of the microwell patterns to support $3 \mathrm{D}$ cell growth was evaluated in terms of the percentage of the cells in each growth category. Cell spreading was analyzed in terms of projection areas under light microscopy. SH-SY5Y cells' VGCC responsiveness was evaluated with confocal microscopy and a calcium fluorescent indicator, Calcium Green ${ }^{\mathrm{TM}}-1$. The expression of L-type calcium channels was evaluated using immunofluorescence staining with DM-BODIPY.

Results: It was found that cells within the microwells, either N2D or 3D, showed more rounded shapes and less projection areas than 2D cells on flat poly (1-lactic acid) substrates. Also, cells in microwells showed a significantly lower VGCC responsiveness than cells on flat substrates, in terms of both response magnitudes and percentages of responsive cells, upon depolarization with $50 \mathrm{mM} \mathrm{K}^{+}$. This lower VGCC responsiveness could not be explained by the difference in L-type calcium channel expression. For the two patterns addressed in this study, N2D cells consistently exhibited an intermediate value of either projection areas or VGCC responsiveness between those for 2D and $3 \mathrm{D}$ cells, suggesting a correlative relation between cell morphology and VGCC responsiveness.

Conclusion: These results suggest that the pattern structure and therefore the cell growth characteristics were critical factors in determining cell VGCC responsiveness and thus provide an approach for engineering cell functionality in cell-based assay systems and tissue engineering scaffolds.

Keywords: replica molding, cell spreading, confocal microscopy, microwell patterns

\section{Introduction}

Cell-based assays are a powerful tool in modern medicine and drug discovery, through which functional information on physiology, pathology, pharmacology as well as toxicity can be obtained in both high-throughput and high-content formats. ${ }^{1-4}$ A great challenge in improving the performance of cell-based assays is ensuring that cells, as the sensing elements of the assay platforms, functionally mirror what happens in vivo. The limitation of traditional flat and two-dimensional (2D) cell culture systems is well recognized, as signaling and functional responses thus achieved may differ from those 
for three-dimensional (3D) systems or in vivo situations. ${ }^{5}$ In the field of experimental oncology, 3D multicellular tumor spheroids have been considered the best in vitro model for mimicking in vivo environments, and even made a mandatory test system for cancer therapeutics screenings. ${ }^{6,7}$ In neuronal cell-based assays, such 3D systems are currently unavailable due to the lack of practical platforms and evaluation of cell functionality under such culture conditions.

Although 3D porous polymer scaffolds and 3D cell cultures are well established in tissue engineering practices, the engineering of 3D cell-based assays has not been possible through the scaling-down of such systems. The fabrication of microstructures or topographic patterns is a practical approach for establishing the 3D cell-based assay systems. In research efforts during the past two decades, such microstructures (eg, microwell patterns) have been fabricated with glass, ${ }^{8}$ silicon, ${ }^{9}$ and polyester photoresist. ${ }^{10}$ These patterns, however, were characterized by low aspect ratios (less than one) or depths (of only 1-2 cell diameters). Thus, they were actually near two-dimensional (N2D) systems as cells were still growing on the flat bottom surface and did not form any $3 \mathrm{D}$ distribution or growth along the depth. It is still an open question whether such near 2D systems are different from the high aspect ratio and 3D systems in terms of the functionality of cells growing therein. Achieving 3D cell growth and evaluating cellular functionality are thus critical tasks in the development of 3D cell-based assay platforms.

We have been interested in the development of 3D neuronal cell-based assay systems targeting voltage-gated calcium channels (VGCCs). Previous studies have shown that VGCC functionality for neuronal cells in 3D structures, for example, SU-8 microwell patterns, ${ }^{11}$ collagen hydrogels, ${ }^{12}$ and Cytodex ${ }^{\circledR}$ microbead arrays, ${ }^{13}$ was different from that of cells under 2D culture conditions. We have also hypothesized that cell VGCC responsiveness or functionality on a microstructured pattern might be related to cell morphology. ${ }^{14}$ However, the capabilities of the fabricated structures or patterns to support 3D cell growth were not evaluated in these studies. Also, inappropriate selection and handling of materials, such as SU-8, ${ }^{11,15}$ for pattern fabrication have resulted in low cytocompatibility and failure of the cells to interface with the 3D structures thus obtained.

Poly (1-lactic acid) (PLLA) is a popular biodegradable polymer that is widely used in clinical practices. This material is attractive in the fabrication of $3 \mathrm{D}$ cell-based platforms because of its well-established high biocompatibility and optical transparency. ${ }^{16-18}$ The adoption of soft lithography also makes it easy to mass produce micropatterns with this material. Also, studies on the interaction of neural cells with PLLA micropatterns provide advantages over those with other pattern materials, as this polymer has already been successfully used for tissue engineering applications and there is a large body of literature available on it. ${ }^{16-18}$

In this study, we adopted ultraviolet (UV) lithography, chemical wet etching, and polydimethylsiloxane (PDMS)based replica molding to fabricate microwell patterns with PLLA. Nine such microwell patterns were designed with diameters of 80,100 , and $120 \mu \mathrm{m}$, a high aspect ratio close to or greater than 1 , either with or without channel connection. SH-SY5Y human neuroblastoma cells were interfaced with the microwell patterns and the capabilities of the patterns to support 3D cell growth were evaluated. We realized that cell growth or distribution on a high aspect ratio microwell pattern can be 2D, 3D, or N2D, based on cell location within the pattern, thus categorized cell growth characteristics accordingly. Cell spreading and VGCC responsiveness were evaluated. Our results indicate that the pattern structure and thus the cell growth characteristics are critical factors in determining cell VGCC functionality. As such, this study provides an approach for engineering cell functionality in cell-based assay systems and tissue engineering scaffolds.

\section{Materials and methods}

\section{Fabrication of PLLA microwell patterns}

Nine microwell patterns were designed and fabricated to ensure that patterns that support both 3D and N2D growth would be found for the interfaced neural cells. These patterns had a nominal well diameter of 80,100 , or $120 \mu \mathrm{m}$, either with or without channels of 20 or $40 \mu \mathrm{m}$ wide, which connected wells as five-well units. (Hereafter, these patterns will be referred to by their well diameter and channel width; for example, " $100-0 \mu \mathrm{m}$ pattern," in which the first number, "100," refers to the well diameter and the " 0 " refers to the channel width.)

Microwell patterns were fabricated with UV lithography, chemical wet etching, and PDMS-based replica molding, as outlined in Figure 1. A quartz chromium mask plate was made by Institute of Microelectronics, Chinese Academy of Sciences (Beijing, China). UV lithography and chemical etching were accomplished with help from No 24 Research Institute of China Electricity Technology Company (Chongqing, China). The master mold was made with a $\mathrm{P}<100>$ silicon wafer with a resistivity of 7-13 $\Omega \cdot \mathrm{cm}$ (Grinm Semiconductor Materials, Beijing, China). Briefly, the production of silicon master mold included the following steps: surface oxidation, photoresist coating, UV lithography and development, wet 


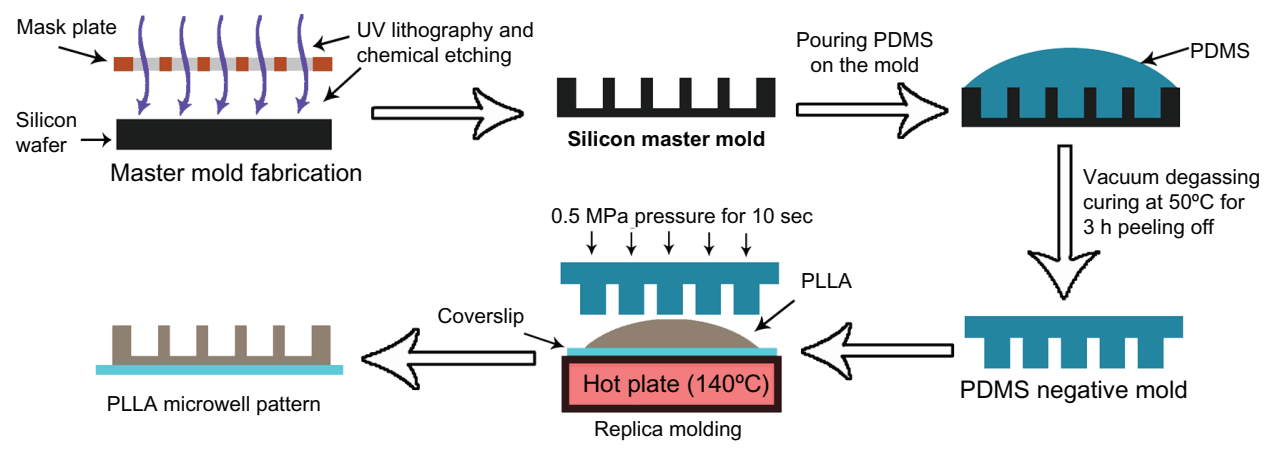

Figure I Schematic illustration of the protocol for fabricating PLLA microwell patterns. Abbreviations: UV, ultraviolet; PDMS, polydimethylsiloxane; PLLA, poly (I-lactic acid).

etching with hydrofluoric acid and Bosch process-based dry etching. The PDMS (Sylgard 184, Dow Corning, Midland, MI, USA) prepolymer and curing agent were mixed in a mass ratio of 10:1, vacuum degassed, and poured on silicon master mold. Samples were vacuum degassed again before placed in $50^{\circ} \mathrm{C}$ oven for 3 hours. After cooling, the PDMS negative mold was stripped from the silicon master mold.

PLLA (Mw = 100,000; Sigma-Aldrich, St Louis, MO, USA) was placed on a coverslip then melted on a heated plate at a temperature of $140^{\circ} \mathrm{C}$. The PDMS negative mold was placed against the melted PLLA and a contact pressure of around $0.5 \mathrm{MPa}$ was imposed on the negative mold for 10 seconds with a pressing machine (TS-C40DX-H, Shenzhen Techson Automation System, Shenzhen, China) to enable the melted PLLA to flow into the structure of the PDMS negative mold. The sample was then immersed in ethyl alcohol for 1 minute. PLLA microwell patterns were obtained after stripping the PDMS negative mold. To serve as a $2 \mathrm{D}$ control for 3D cell growth on microwell patterns, PLLA flat substrates were fabricated using the same protocols as for those for PLLA microwell patterns, except that the PDMS negative mold was replaced with a flat PDMS substrate.

\section{Cell culture and cell growth characteristics}

SH-SY5Y human neuroblastoma cells were obtained from the ATCC (Manassas, VA, USA) and routinely cultured in $75 \mathrm{~cm}^{2}$ tissue culture flasks (Costar, Corning, NY, USA) with $30 \mathrm{~mL}$ growth medium at $37^{\circ} \mathrm{C}$ in a $5 \% \mathrm{CO}_{2}$ humidified atmosphere. Growth medium was made with complete Roswell Park Memorial Institute (RPMI)-1640 medium containing 10\% heat-inactivated fetal bovine serum (FBS) (Gibco, Gaithersburg, MD, USA). At 75\% confluence, the cells were detached using $0.25 \%$ trypsin (Hyclone, Logan, UT, USA) and re-suspended in growth medium for plating. Before plating, the PLLA microwell patterns and flat substrates were sterilized with $70 \%$ ethanol in deionized (DI) water under UV light overnight, washed twice with 4-(2-hydroxyethyl)1-piperazineethanesulfonic acid (HEPES)-buffered saline (HBS) then bathed with FBS for at least 1 hour to enhance cell attachment. The patterns or flat substrates were then washed with growth media twice. Approximately $5 \times 10^{5}$ of cells in $3 \mathrm{~mL}$ growth medium were plated on each patterned or flat substrate, which was contained in a $35 \mathrm{~mm}$ Petri dish (Falcon, Becton Dickinson Labware, Franklin Lakes, NJ, USA). Light microscopic images for the interfaced cells were taken on a Leica DMI 4000B inverted microscope (Leica Microsystems, Wetzlar, Germany) with a charge-coupled device (Leica DFC 300FX, Leica Microsystems) or an Olympus CKX41 inverted microscope (Olympus Optical, Tokyo, Japan) with a Canon PC1200 digital camera (Tokyo, Japan).

After seeding on patterned or flat substrates for 2 days, the capability of the patterns to support 3D cell growth was evaluated. We found that cells grew both on the top surfaces and inside the microwells. With our patterns, cells inside the microwells were found to attach both to the bottom surface and on the side wall, or along the well depth. We thus counted the cells on the pattern and categorized cell growth characteristics as $2 \mathrm{D}, 3 \mathrm{D}$, and $\mathrm{N} 2 \mathrm{D}$, according to their location within the pattern. Cells on the top surface of the pattern were considered $2 \mathrm{D}$, while cells attaching to the bottom surface of the well were categorized as N2D. Cells attaching to the side wall of the microwells were categorized as $3 \mathrm{D}$ when they were at least one cell diameter away from the bottom surface, judged by focusing with a microscope. Otherwise, cells were categorized as N2D even if they were in contact with the side wall, although this situation was rare in our experiments. The percentage of cells in each category was computed by dividing the number of cells counted in that category by the total number of cells counted. For each pattern, 20 fields under a $20 \times$ objective were counted and percentages were averaged across the fields counted. 
Cell spreading was evaluated in terms of cellular projection areas and perimeters. Light microscopic images were captured after Calcium Green ${ }^{\mathrm{TM}}$-1 loading and before calcium imaging for VGCC responsiveness. For 3D and N2D cells in the microwell patterns, the overlay of confocal images helped identify cells within the confocal plane in the light microscopic images, enabling morphological measurements on the same cells as those for VGCC responsiveness evaluation. Projection areas and perimeters were measured with Image J software ${ }^{19}$ by tracking the cell contours enclosing the cell bodies and lamellipodia. Roundness was defined as $4 \times \pi \times$ area/(perimeter). ${ }^{2}$

\section{Scanning electron microscopy (SEM)}

Cells in PLLA patterns were fixed with 2\% glutaraldehyde in $0.1 \mathrm{M}$ sodium cacodylate buffer, $\mathrm{pH} 7.2$ for 1 hour before rinsing in cacodylate buffer (without glutaraldehyde) three times for 15 minutes each time. This was followed by $0.9 \%$ sodium chloride rinsing twice for 6 minutes each time. The samples were then dehydrated successively in 30\%, 50\%, 70\%, 80\%, 95\%, and $100 \%$ ethanol twice for 5 minutes each time. Mounting concentrations, $50 \%, 70 \%, 90 \%, 95 \%$, and $100 \%$, of tertiary butanol were used to rinse the samples twice for 5 minutes each time. Then the samples were sputter coated with gold three to five times for 20 seconds each time. SEM images were captured with scanning electron microscope (S-3400 N, Hitachi, Tokyo, Japan) with an acceleration voltage of $15 \mathrm{kV}$.

\section{Evaluation of VGCC responsiveness}

The membrane permeable fluorescent dye Calcium Green-1acetoxymethylester (AM) (Invitrogen, Carlsbad, CA, USA), was used to visualize the calcium influx dynamics. After 2 days of culture on either flat or patterned substrates, SH-SY5Y cells were washed twice with HBS then loaded with $5 \mu \mathrm{M}$ Calcium Green-1 (AM) in $1 \mathrm{~mL}$ of HBS, which contained 3\% heatinactivated FBS and $0.02 \%$ Pluronic ${ }^{\circledR}$ F-127 (Invitrogen), for 1 hour at $37^{\circ} \mathrm{C}$ in a $5 \% \mathrm{CO}_{2}$ humidified incubator. Following this, the cells were washed twice with HBS and incubated with $1 \mathrm{~mL} \mathrm{HBS}$ at $37^{\circ} \mathrm{C}$ in the $5 \% \mathrm{CO}_{2}$ humidified incubator for another hour to allow complete dye de-esterification. Coverslips containing the cells were transferred to a chamber (locally made in our laboratory) on the stage of an inverted microscope and intracellular $\mathrm{Ca}^{2+}$ dynamics were monitored with a confocal laser scanning system (TCS-SP5; Leica). The Calcium Green-1 was excited with a $488 \mathrm{~nm}$ argon laser and the emission was captured through a $515 \mathrm{~nm}$ long pass filter. Time series (150 seconds) of full-frame images $(512 \times 512$ pixels $)$ were acquired in the optimal focal plane at a rate of one frame per 3 seconds. After a 30-second recording, high $\mathrm{K}^{+}(135.5 \mathrm{mM})$ depolarizing HBS solution, in which $\mathrm{NaCl}$ had been iso-osmotically replaced with $\mathrm{KCl}$, was added to the sample (with a normal $\mathrm{K}^{+}$concentration of $5 \mathrm{mM}$ ) to achieve a final $\mathrm{K}^{+}$concentration of $50 \mathrm{mM}$. VGCC fractional response magnitudes were measured from the $\mathrm{Ca}^{2+}$ transients as the fluorescence intensity ratio:

$$
\Delta F / F=\left(F-F_{\text {pre }}\right) /\left(F_{\text {pre }}-F_{\text {bgnd }}\right)
$$

where $F$ represents peak fluorescence intensity after high $\mathrm{K}^{+}$depolarization, $F_{\text {pre }}$ is the average fluorescence intensity measured during the pre-stimulus period, and $F_{\text {bgnd }}$ is the background fluorescence measured in background solution without dye..$^{20} \mathrm{~A}$ detailed measurement of the dynamics of the fluorescence response curve (peak width at half height and peak area) is provided in the Appendix.

\section{Immunofluorescence for L-type calcium channel expression}

L-type calcium channel expression was evaluated in terms of the dihydropyridine-binding site distribution, which reflects the cell L-type channel density. ${ }^{21}$ For staining, the samples were washed with HBS twice and then incubated for 1 hour with $2 \mu \mathrm{M}$ of the L-type $\mathrm{Ca}^{2+}$ channel dye DM-BODIPY (Molecular Probes, Eugene, OR, USA) in $\mathrm{HBS}$ at $37^{\circ} \mathrm{C}$. Cells were then washed with HBS twice. Immunofluorescence images of the samples were captured using the Leica TCSSP5 confocal laser scanning system and fluorescence intensities were measured for all the cells in view. DM-BODIPY was excited with a $488 \mathrm{~nm}$ argon laser and the emission was captured through a 515-540 nm band-pass filter.

To compare the cellular expression of L-type calcium channels, a procedure applied to flow cytometry data processing was adopted.22 The cellular mean fluorescence intensities for each set of data were calculated and cells with fluorescence intensity in the seventy-fifth percentile or higher were scored as strongly positive for L-type channel expression. Although arbitrary, the choice of seventy-fifth percentile for comparative purposes has proved very sensitive when only small differences exist among cells. ${ }^{22}$ The total number of cells strongly expressing L-type channel was determined for cells on flat substrates and in microwell patterns for statistical comparisons.

\section{Statistics}

Data pertaining to percentages in each growth category, cell projection areas and VGCC response magnitudes were expressed as mean \pm standard deviation. Student's $t$-test was 
used for comparisons of the mean values of the growth percentages and projection areas between cells on flat substrates and in microwell patterns or among cells of different growth categories. Statistical comparisons of VGCC response magnitudes were made with one-way analysis of variance. The nonparametric Mann-Whitney U test was used to compare the frequency distributions for the VGCC response magnitudes and percentages of cells with strong L-type channel expression. Differences were considered statistically significant when the $P$ value (two-sided) was $<0.05$.

\section{Results and discussion Fabrication of the PLLA microwell patterns}

PLLA is a popular biodegradable polymer with excellent biocompatibility ${ }^{16-18}$ and, when properly structured, it supports various forms of scaffolds including membrane, ${ }^{23}$ nanofiber, ${ }^{24}$ or sponge ${ }^{25,26}$ for tissue engineering purposes. However, the establishment of 3D cell-based assays with the same scaleddown materials is not automatic for the following reasons. First, the production of random and un-patterned structures usually results in a reduction or loss of optical transparency, making it hard for the scaffold to be compatible with current optical screening readouts. Second, a mass scaffold production protocol usually fails to achieve 3D structures with well-controlled dimensions and aspect ratios. Third, the limited mass transportation in the porous or sponge scaffolds significantly compromises the nutrient supply, waste drainage, and drug exposure as well as fluorescence staining.

In the present study, we adopted a lithography-based replica molding method to fabricate microwell patterns with PLLA for the development of 3D neuronal cell-based assay platforms. Successful fabrication of microwell patterns and interfacing with neural cells (ie, progenitors) can also find application in stem cell transplantation or tissue engineering scaffold establishment. ${ }^{27}$ To enable a study of the effects of pattern structure and dimension on cell growth characteristics, our patterns were designed both with and without channel connections. Also, to ensure that we would find the most favorable patterns for 3D cell interfacing, graded geometric dimensions with well diameters of 80,100 , and $120 \mu \mathrm{m}$, and channel widths of 0 (no channel connection), 20 , and $40 \mu \mathrm{m}$ were designed and thus nine patterns were obtained. Our decision to use a well diameter of around $100 \mu \mathrm{m}$ was based on previous studies with SU-8 microwell patterns, ${ }^{11,15}$ in which smaller wells of $50 \mu \mathrm{m}$ were found ineffective for cell interfacing. Figure 2A-C shows representative microwell patterns fabricated in this study with a well diameter of $100 \mu \mathrm{m}$ and either without (A) or with channel connection (B and $\mathrm{C}$ ). For those without channel connection (A), patterns were just simple arrays of microwells and were expected to support 3D cell growth for neuronal cells before induction of neuronal extensions. Patterns with channel connection were composed of arrays of five-well units connected through channels $20 \mu \mathrm{m}$ (B) or $40 \mu \mathrm{m}$ (C) wide. These patterns were expected to both support 3D cell growth and accommodate neuronal extensions after induction of morphological differentiation. The patterns showed clear and high-quality structures with dimensions fulfilling our original design specifications. Also, a high aspect ratio of approximately one was achievable through the current fabrication protocols, which rendered our patterns quasi-3D (A). Our ongoing investigations indicate that this protocol also works well for the fabrication of patterns with other polymers, like poly(DL-lactide-co-glycolide). ${ }^{28}$

\section{Interfacing of $\mathrm{SH}-\mathrm{SY} 5 \mathrm{Y}$ cells with the microwell patterns}

Figure 3A-D shows phase contrast images taken after 2 days of culture in growth medium and demonstrates that the SH-

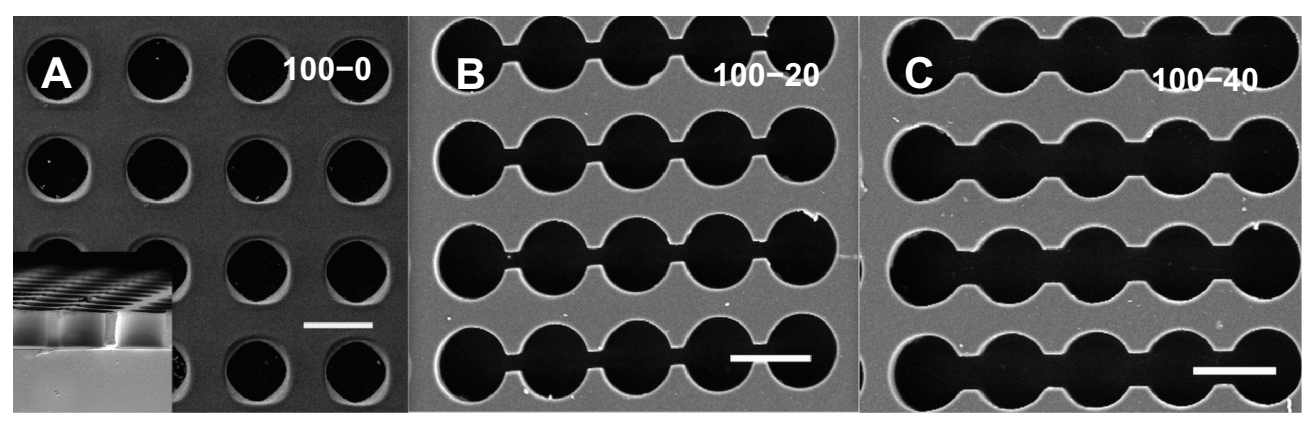

Figure 2 SEM images for PLLA microwell patterns.

Notes: The numbers on each image are microwell diameter-channel width in micrometers. Scale bar $=100 \mu \mathrm{m}$.

Abbreviations: SEM, scanning electron microscopy; PLLA, poly (I-lactic acid). 


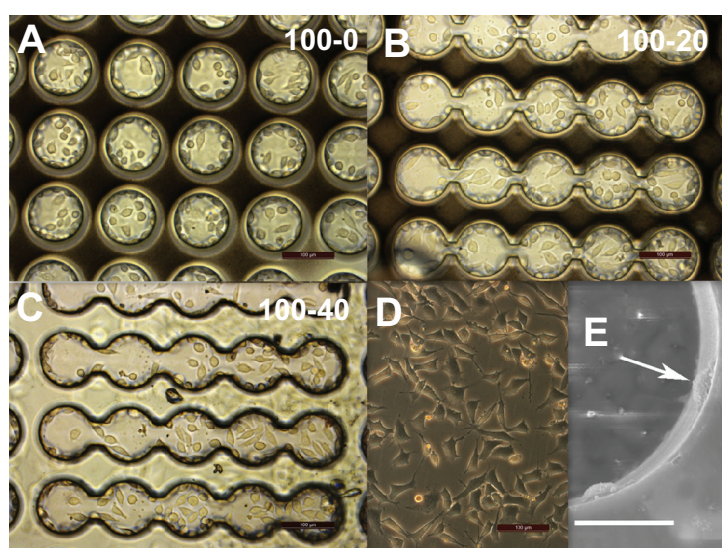

Figure 3 Interfacing of SH-SY5Y cells with PLLA microwell patterns. Patterns used had a well diameter of $100 \mu \mathrm{m}$ and a channel width of 0 (without channel, A), 20 (B) and 40 (C) $\mu \mathrm{m}$. Image (D) shows SH-SY5Y cells growing on a flat substrate. Image (E) shows an SEM micrograph of 3D cells attaching on the side wall of the well (arrow).

Notes: The numbers on the images are microwell diameter-channel widths in micrometers. Images were taken after 2 days of culture in growth medium. Scale bar $=100 \mu \mathrm{m}(\mathrm{A}$ through $\mathrm{D})$ or $30 \mu \mathrm{m}(\mathrm{E})$.

Abbreviations: PLLA, poly (I-lactic acid); SEM, scanning electron microscopy; $3 \mathrm{D}$, three dimensional.

SY5Y cells grew well either in the PLLA microwell patterns (A-C) or on the PLLA flat substrates (D). From these images, we determined that the cells inside the wells of the pattern had a more rounded shape than the cells on the flat substrates, suggesting that geometrical confinement inside the microwells affected cell spreading. The SH-SY5Y cell line is an adrenergic "N"-type clone of the "mixed cell" human neuroblastoma line SK-N-SH and has been used extensively in common 2D cultures to study neuronal function, growth, damage in response to insult, degeneration, and differentiation. ${ }^{29-32}$ Under regular culture conditions, SH-SY5Y cells are difficult to culture as multicellular aggregates and are easily prepared as single cell suspensions. To our knowledge, reports of the culture of SH-SY5Y cells as significant multi- cellular tumor spheroids for practical research and application purposes are rare..$^{33}$ In view of this, we were not expecting that the current cell line would form 3D cellular aggregates in our microwell patterns, in contrast to our findings with hippocampal neural progenitors ${ }^{28}$ and $\mathrm{c} 17.2$ neural stem cells (unpublished results). Consequently, we defined and categorized cell growth characteristics as 2D, 3D, and N2D based on cell location or distribution within the pattern, as described in the Materials and methods section.

Table 1 shows a comparison of cell growth characteristics in terms of the percentages of each growth category for the nine patterns. It was found that only three patterns with a well diameter of $100 \mu \mathrm{m}$ had a 3D growth percentage close to or greater than $30 \% 2$ days after cell plating. Patterns with a well diameter of $100 \mu \mathrm{m}$ had higher percentages of 3D cells than their counterparts with the same channel dimension (or without channels) but with a well diameter of $80 \mu \mathrm{m}$ or $120 \mu \mathrm{m}(P<0.05)$. Among the three patterns with a well diameter of $100 \mu \mathrm{m}$, the $100-0 \mu \mathrm{m}$ and $100-20 \mu \mathrm{m}$ patterns accommodated $60.4 \%$ and $63 \%$, (N2D + 3D) cells, respectively, which was in contrast to a lower percentage of $48.8 \%$ for the $100-40 \mu \mathrm{m}$ pattern. The $100-40 \mu \mathrm{m}$ pattern exhibited a lower 3D percentage $(29.2 \% \pm 10.5 \%)$ than the $100-20 \mu \mathrm{m}$ $(37.9 \% \pm 10.4 \%)(P<0.05)$ and $100-0 \mu \mathrm{m}(34.5 \% \pm 12 \%)$ $(P>0.05)$ patterns. These results suggest that the pattern structure and dimensions had profound effects on the growth characteristics of the interfaced SH-SY5Y cells, with the patterns with a well diameter of $100 \mu \mathrm{m}$ - especially the $100-0 \mu \mathrm{m}$ and $100-20 \mu \mathrm{m}$ patterns - the most favorable patterns for accommodating cells inside the microstructures. Thus, these two patterns were used to study the spreading and VGCC responsiveness for SH-SY5Y cells in 3D microwell patterns in the following sections.

Table I Percentages of 2D, N2D and 3D cells 2 days after plating SH-SY5Y cells onto the microwell patterns

\begin{tabular}{|c|c|c|c|c|}
\hline PLLA patterns & 3D cells & N2D cells & 2D cells & $\mathbf{n}$ \\
\hline $80-0 \mu \mathrm{m}$ & $23.4 \% \pm 9.1 \%$ & $24.1 \% \pm 6.5 \%$ & $52.5 \% \pm 10 \%$ & 755 \\
\hline $100-0 \mu \mathrm{m}$ & $34.5 \% \pm 12 \%^{a}$ & $25.9 \% \pm 8.5 \%$ & $39.6 \% \pm 9.8 \%^{a}$ & 776 \\
\hline $120-0 \mu \mathrm{m}$ & $17.5 \% \pm 3.4 \% \%^{a, b}$ & $40.5 \% \pm 10.6 \%$ & $42 \% \pm 12.5 \%$ & 690 \\
\hline $80-20 \mu \mathrm{m}$ & $24.1 \% \pm 6.7 \%$ & $14.6 \% \pm 8.7 \%^{c}$ & $61.3 \% \pm 10.8 \% c$ & 707 \\
\hline $100-20 \mu \mathrm{m}$ & $37.9 \% \pm 10.4 \%^{a}$ & $25 \% \pm 8.3 \%^{\mathrm{a}}$ & $37 \% \pm 13.7 \%^{a}$ & 716 \\
\hline $120-20 \mu \mathrm{m}$ & $21.7 \% \pm 9.9 \%$ & $25.4 \% \pm$ I I. $5 \% \%^{a, c}$ & $52.9 \% \pm 16.2 \%$ b,c & 810 \\
\hline $80-40 \mu \mathrm{m}$ & $21.3 \% \pm 9.1 \%$ & $25.6 \% \pm 11.6 \%^{d}$ & $53 \% \pm 19 \%$ & 784 \\
\hline $100-40 \mu \mathrm{m}$ & $29.2 \% \pm 10.5 \%$ a,d & $19.6 \% \pm 5.4 \%$ a,c,d & $51.2 \% \pm 10.5 \%$,d & 677 \\
\hline $120-40 \mu \mathrm{m}$ & $22.1 \% \pm 10.7 \%$ & $44.2 \% \pm 16 \% \%^{a, b, d}$ & $33.8 \% \pm 17.4 \% \frac{a, b, d}{}$ & 658 \\
\hline
\end{tabular}

Notes: The numbers in the left column refer to well diameter-channel widths in micrometers for the patterns. Percentage $=$ number of cells in each category/total cell number counted. Statistically significant difference probability values for comparison with the pattern with a well diameter of $80 \mu$ m: ${ }^{\text {a }} P<0.05$. Statistically significant difference probability values for comparison with the pattern with a well diameter of $100 \mu \mathrm{m}$ : ${ }^{b} P<0.05$. Statistically significant difference probability values for comparison with the pattern without channels: ${ }^{c} P<0.05$. Statistically significant difference probability values for comparison with the pattern with a channel width of $20 \mu$ m: ${ }^{d} P<0.05$. A total of 20 fields under a $20 \times$ objective were counted for each pattern and percentages were averaged across the counted fields.

Abbreviations: PLLA, poly (I-lactic acid); 2D, two dimensional; N2D, near two dimensional; 3D, three dimensional; $n$, total number of cells counted. 
The biological behavior of cells can be significantly affected by the addition of micro and nano features on the culture substrates. ${ }^{34}$ For a patterned substrate, these features can be represented by the pattern structure and pattern dimensions. Our results indicate that the effects of pattern structure on the growth characteristics cannot be fully attributed to the difference in the top surface areas or opening areas of the patterns, as the introduction of channel connection or the increase in well diameter did not readily result in a decrease of the percentage for $2 \mathrm{D}$ cells or an increase of the percentage of 3D + N2D cells. The well and channel structures might play a major role in this regard. In view of this, the defining of N2D growth and a distinction between N2D and 3D growth is necessary, as different locations within the pattern represented different microenvironments, as exemplified by substrate properties such as surface curvature, which might result in different cellular functionality (see the following two subsections). Accordingly, patterns that have been suggested to support three-dimensionality might actually be supporting N2D growth. ${ }^{35,36}$

\section{The spreading of SH-SY5Y cells on the PLLA microwell patterns}

We quantitatively characterized the spreading of the interfaced SH-SY5Y cells in our microwell patterns to further understand the effects of the pattern structure on cell morphology. The significance of the evaluation of cell spreading lies in the fact that morphological changes are the earliest and easiest-to-detect events that respond to changes in substrate structure or properties. Bettinger et al even proposed that changes in cell spreading are the primary cellular response to substrate topography that form the basis of, and initiate, the further biochemical and genomic events upon plating on a topographic substrate. ${ }^{37}$ Because of the concern that cells on a high aspect ratio topographic substrate are in different focal depths under SEM, and due to the loss of cells while preparing cross-sectional samples for SEM, our current evaluation of cell spreading was based on the projection areas under light microscopy. A concern over the current measurement may be that the quantification of the projection areas might ignore the effects of neuronal extensions on cell spreading measurements. However, this has been reduced to a minimum by limiting the measurements to cells before morphological differentiation. For 3D and N2D cells in the microwell patterns, the overlay of confocal images helped identify cells within the confocal plane in the light microscopic images, enabling morphological measurements of the same cells as those used for calcium imaging. This enabled the establishment of correlative relation between cell spreading and VGCC responsiveness (see the following subsection). This is in contrast to a previous study in which cell spreading and VGCC responsiveness were evaluated with separate cell populations. ${ }^{14}$

Table 2 shows the cell morphological measurements based on the light microscopic images (Figures 3 and 4). The table shows that for either of the two patterns studied, the N2D and 3D cells in the microwells had significantly decreased projection areas but increased roundness values in comparison to the 2D cells after 2 days of culture $(P<0.01)$. For the $100-0 \mu \mathrm{m}$ pattern, the projection area of the N2D cells was $198 \pm 60 \mu \mathrm{m}^{2}(\mathrm{n}=62)$, which was significantly higher than that of the $3 \mathrm{D}$ cells $\left(148 \pm 46 \mu \mathrm{m}^{2}, \mathrm{n}=48\right)$ $(P<0.01)$ but lower than that of the $2 \mathrm{D}$ cells $\left(461 \pm 223 \mu \mathrm{m}^{2}\right.$ $\mathrm{n}=71)(P<0.01)$. The same trend was also found for the 100-20 $\mu \mathrm{m}$ pattern, where the projection area for the N2D cells was between that of the $3 \mathrm{D}$ and $2 \mathrm{D}$ cells. Table 2 also shows that the projection areas for the N2D and 3D cells on the 100-20 $\mu \mathrm{m}$ pattern $\left(161 \pm 42 \mu \mathrm{m}^{2}, \mathrm{n}=65\right.$ and $122 \pm 41 \mu \mathrm{m}^{2}, \mathrm{n}=89$, respectively), were significantly lower than those for the N2D and 3D cells on the 100-0 $\mu \mathrm{m}$ pattern $\left(198 \pm 60 \mu \mathrm{m}^{2}, \mathrm{n}=62, P<0.05\right.$ and $148 \pm 46 \mu \mathrm{m}^{2}$, $\mathrm{n}=48, P<0.05$, respectively). However, the N2D cells on

Table 2 Summary of morphological measurements for SH-SY5Y cells on flat surfaces and in microwell patterns

\begin{tabular}{|c|c|c|c|c|c|}
\hline & \multirow{2}{*}{$\frac{\text { FS }}{2 D}$} & \multicolumn{2}{|c|}{ Patterns of $100-0 \mu \mathrm{m}$} & \multicolumn{2}{|c|}{ Patterns of $100-20 \mu \mathrm{m}$} \\
\hline & & N2D cells & 3D cells & N2D cells & 3D cells \\
\hline $\mathrm{PA}\left(\mu \mathrm{m}^{2}\right)$ & $46 I \pm 223(n=7 I)$ & $198 \pm 60^{\mathrm{a}}(\mathrm{n}=62)$ & $148 \pm 46^{\mathrm{a}, \mathrm{c}}(\mathrm{n}=48)$ & $16 \mid \pm 42^{a, b}(n=65)$ & $|22 \pm 4|^{a-c}(n=89)$ \\
\hline $\operatorname{Per}(\mu \mathrm{m})$ & $104 \pm 36(n=71)$ & $55 \pm 12^{\mathrm{a}}(\mathrm{n}=62)$ & $48 \pm 8^{a, c}(n=48)$ & $48 \pm 7^{\mathrm{a}, \mathrm{b}}(\mathrm{n}=65)$ & $46 \pm 9^{a}(n=89)$ \\
\hline Roundness & $0.57 \pm 0.19(n=71)$ & $0.84 \pm 0.12^{\mathrm{a}}(\mathrm{n}=62)$ & $0.8 \mathrm{I} \pm 0.1 \mathrm{I}^{\mathrm{a}}(\mathrm{n}=48)$ & $0.85 \pm 0.09^{a}(n=65)$ & $0.72 \pm 0.15^{a-c}(n=89)$ \\
\hline
\end{tabular}

Notes: The numbers 100-0 and 100-20 indicate well diameter-channel widths in micrometers for the patterns. Roundness is defined as $4 \times \pi \times$ area/(perimeter) ${ }^{2}$. Measurements were based on light microscopic images as described in Materials and Methods Section. The perimeter was drawn by tracking the cell contours enclosing the cell bodies and lamellipodia. Statistically significant difference probability values for comparison with cells on flat substrates: ${ }^{2} P<0.01$. Statistically significant difference probability values for comparison with cells on the $100-0$ patterns: ${ }^{b} P<0.05$. Statistically significant difference probability values for comparison with $\mathrm{N} 2 \mathrm{D}$ cells on the same pattern: $c P<0.01$.

Abbreviations: FS, flat substrates; PA, projection area; Per, perimeter; 2D, two dimensional; N2D, near two dimensional; 3D, three dimensional; n, number of cells measured. 


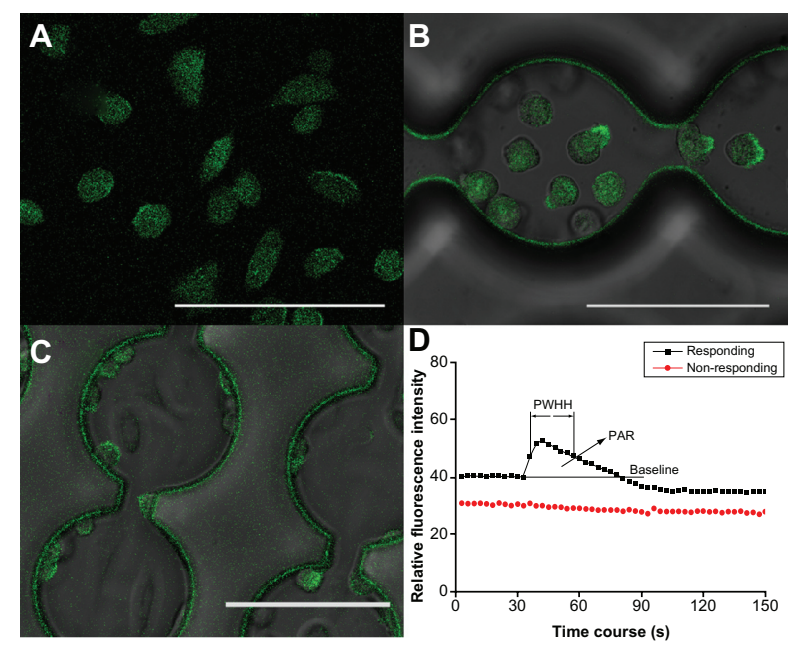

Figure 4 Confocal images of 2D cells on PLLA flat substrates after Calcium green-I loading (A) and overlay of the confocal images and the light microscopic images for N2D (B) and 3D (C) cells in the PLLA microwell patterns. The overlay of fluorescence helped identify cells both within and out of the confocal plane in the light microscopic images, and those within the focal plane were chosen for morphological measurements. Calcium imaging curves in (D) represent a typical plot of changes in relative intracellular Calcium Green-I fluorescence intensity for a responsive and a non-responsive SH-SY5Y cell on 2D PLLA substrates upon $50 \mathrm{mM} \mathrm{K} \mathrm{K}^{+}$depolarization on day 2 after cell plating. A cell was only considered responsive when it showed a fractional increase in Calcium Green-I fluorescence intensity of 0.15 or higher over the basal fluorescence intensity level. Also shown in (D) are the measurements of PWHH and PAR for the dynamics of the fluorescence response curve.

Notes: See the Supplementary Methods and Results Section for details. Scale bar $=100 \mu \mathrm{m}(\mathrm{A}-\mathrm{C})$.

Abbreviations: PLLA, poly (l-lactic acid); 2D, two dimensional; N2D, near two dimensional; 3D, three dimensional; PWHH, peak width at half height; PAR, peak area.

the 100-0 and 100-20 $\mu \mathrm{m}$ patterns showed a similar roundness $(P>0.05)$, while the 3D cells on the $100-0 \mu \mathrm{m}$ pattern had a larger roundness than the 3D cells on the 100-20 $\mu \mathrm{m}$ pattern $(P<0.05)$.

Some of the simplest examples of the influence of microstructures on cell shape have emerged from the development of 3D culture systems for tissue engineering applications. These systems generally induce more rounded cell morphology in comparison to standard 2D culture systems. ${ }^{38}$ This is in agreement with our findings, as the cells cultured inside microwells had less projection areas but larger roundness values than the cells on flat substrates and the 3D cells had even smaller projection areas than the N2D cells. One may be concerned that the projection of the $3 \mathrm{D}$ cells along the depth of the microstructure might compromise the estimation of cell spreading, as the cells actually attached and spread on the side wall of the wells. However, given the fact that the N2D cells were confined by only a growth boundary (side wall), while the $3 \mathrm{D}$ cells were confined by both the growth boundary and the concave surface of the side wall, the smaller projection areas of the 3D cells compared with those of the N2D cells are understandable.

\section{VGCC responsiveness of SH-SY5Y cells in microwell patterns versus on flat substrates}

We evaluated the cell functionality of the interfaced SHSY5Y cells in the microwell patterns in terms of VGCC responsiveness. VGCCs have been an emerging important drug target, as the dysfunction of VGCCs has proved to be related to diseases in the cardiovascular, central nervous, endocrine, and other systems. ${ }^{39}$ With the predominant adoption of fluorescence-based detection in cell-based screening programs, the present study was carried out with a calcium fluorescent indicator combined with laser scanning confocal microscopy. Figure 4 shows confocal images of 2D cells on PLLA flat substrates (A), the overlay of the confocal fluorescence on light microscopic images for N2D (B) and 3D (C) cells on microwell patterns after Calcium Green-1 loading, as well as a typical plot for changes in cytoplasmic Calcium Green-1 fluorescence intensity for both a responding and non-responding SH-SY5Y cell upon $50 \mathrm{mM}$ high $\mathrm{K}^{+}$ depolarization (D). A cell was only considered to be responding when it showed a fractional increase in Calcium Green-1 fluorescence intensity of 0.15 or higher over the basal fluorescence intensity level upon high $\mathrm{K}^{+}$stimulation.

Table 3 summarizes the calculated percentages of responding cells and the response magnitudes for 2D cells on flat substrates as well as N2D and 3D cells in both the $100-0 \mu \mathrm{m}$ and 100-20 $\mu \mathrm{m}$ patterns. The response magnitudes were calculated using Equation 1 by including only the responding or responsive cells and excluding nonresponsive cells. The table shows that the response magnitudes for $2 \mathrm{D}$ cells on flat substrate were $0.43 \pm 0.15(n=65)$, which were or tended to be higher than those for N2D $(P<0.05$ for the $100-0 \mu \mathrm{m}$ pattern but $P>0.05$ for the $100-20 \mu \mathrm{m}$ pattern) and $3 \mathrm{D}$ $(P<0.05)$ responsive cells in both the two patterns. For either the $100-0 \mu \mathrm{m}$ or the $100-20 \mu \mathrm{m}$ pattern, response magnitudes for N2D cells were or tended to be higher than those for 3D cells in the same pattern. Response magnitudes for N2D and 3D cells in the 100-20 $\mu \mathrm{m}$ pattern tended to be higher than those for their counterparts in the $100-0 \mu \mathrm{m}$ pattern, but this difference was not statistically significant $(P>0.05)$.

To further characterize the VGCC responsiveness for cells in our microwell patterns, the nonparametric two-sample Mann-Whitney U test was used to compare the frequency distributions of responding magnitudes for 2D cells on flat substrates with those for the N2D and 3D cells in the 100-0 $\mu \mathrm{m}$ and 100-20 $\mu \mathrm{m}$ patterns. From the frequency distribution analysis and Table 3 , we found that $91.5 \%$ of the $2 \mathrm{D}$ cells on 
Table 3 Percentages of VGCC responsive SH-SY5Y cells on flat substrates and in microwell patterns with respect to response magnitudes upon $50 \mathrm{mM} \mathrm{K+}$ depolarization

\begin{tabular}{|c|c|c|c|c|c|}
\hline & \multirow{2}{*}{$\frac{\text { FS }}{2 D}$} & \multicolumn{2}{|c|}{ Patterns of $100-0 \mu \mathrm{m}$} & \multicolumn{2}{|c|}{ Patterns of $100-20 \mu \mathrm{m}$} \\
\hline & & N2D cells & 3D cells & N2D cells & 3D cells \\
\hline PCR & $65 / 71=91.5 \%$ & $5 \mathrm{I} / 62=82.3 \%^{\mathrm{a}}$ & $36 / 48=75 \% a, b$ & $54 / 65=83.1 \%^{a}$ & $52 / 89=58.4 \%$ a,b \\
\hline RM & $0.43 \pm 0.15(n=65)$ & $0.37 \pm 0.18^{a}(n=51)$ & $0.30 \pm 0.12^{\mathrm{a}}(\mathrm{n}=36)$ & $0.40 \pm 0.19(n=54)$ & $0.36 \pm 0.17^{a}(n=52)$ \\
\hline
\end{tabular}

Notes: A cell was only considered responsive when it showed a fractional increase in Calcium Green-I fluorescence intensity of 0.15 or higher over the basal fluorescence intensity level upon high $\mathrm{K}^{+}$depolarization. The percentage of responsive cells (PCR) is expressed as: (number of responding cells)/(total number of cells measured) = PCR. RMs were pooled and presented by including responsive cells and excluding non-responsive cells. Statistically significant difference probability values for comparison with cells on flat substrates: ${ }^{a} P<0.05$. Statistically significant difference probability values for comparison with N2D cells on the same pattern: ${ }^{b} P<0.05$.

Abbreviations: FS, flat substrates; PCR, percentage of responsive cells; RM, response magnitude; 2D, two dimensional; N2D, near two dimensional; 3D, three dimensional; $\mathrm{n}$, number of cells measured.

flat substrates were responsive to high $\mathrm{K}^{+}$. This percentage was significantly higher than those for $\mathrm{N} 2 \mathrm{D}$ and $3 \mathrm{D}$ cells on either the $100-0 \mu \mathrm{m}$ or the $100-20 \mu \mathrm{m}$ pattern $(P<0.05)$. On the $100-0 \mu \mathrm{m}$ pattern, the percentage of responsive N2D cells was $82.3 \%$, which was significantly higher than that of 3D cells on the same pattern $(75 \%)(P<0.05)$. On the 100-20 $\mu \mathrm{m}$ pattern, $83.1 \%$ of the N2D cells were responsive, which was in contrast to the lower percentage of $58.4 \%$ for 3D cells $(P<0.05)$. Frequency distribution analysis also showed that N2D cells on the $100-0 \mu \mathrm{m}$ pattern tended to have a lower percentage of responding cells than N2D cells on the $100-20 \mu \mathrm{m}$ pattern ( $82.3 \%$ vs $83.1 \%, P>0.05)$. In contrast, 3D cells on the $100-0 \mu \mathrm{m}$ pattern had a higher percentage of responsive cells than 3D cells on the 100-20 $\mu \mathrm{m}$ pattern ( $75 \%$ vs $58.4 \%, P<0.05)$.

The above results show that cells in the microwells, either 3D or N2D, are less responsive than cells on flat substrates (2D), in terms of both fluorescence response magnitudes and percentages of responsive cells, and 3D cells are even less responsive than N2D cells. This is also supported by the measurement of the peak areas (PARs) for the fluorescence response curves (see Appendix). The present finding is in agreement with our previous study of SU-8 microwell patterns, in which the percentage of responsive cells on flat substrates was significantly higher than that of cells in microwells. ${ }^{11}$ However, a distinction between the VGCC responsiveness of N2D cells and that of 3D cells suggests that cell growth characteristics significantly affected cellular functionality and cells of the N2D growth category were not functionally identical to cells of the 3D growth category.

\section{L-type calcium channel staining}

Numerous types of VGCCs have been documented in SHSY5Y cells using either a patch-clamp technique ${ }^{40,41}$ or fluorescence recording. ${ }^{42,43}$ Using high $\mathrm{K}^{+}$depolarization and a Fura-2-based fluorescence imaging technique, Lambert et $\mathrm{al}^{42}$ found that L-type channels may contribute to an increase in $\left[\mathrm{Ca}^{2+}\right]_{\mathrm{i}}$ in a wide range of depolarization (by 30 to $60 \mathrm{mM} \mathrm{K}^{+}$) in SH-SY5Y cells, while N-type channels may only contribute to this increase at a higher depolarization (by $60 \mathrm{mM} \mathrm{K}^{+}$). N-type channels have also been found to be fully inactivated in a dorsal root ganglion preparation at patch clamp, holding potentials positive to $-50 \mathrm{mV}^{44} \mathrm{Ca}^{2+}$ entry through L-type channels in SH-SY5Y cells has thus been suggested to play a major role in the rise in $\left[\mathrm{Ca}^{2+}\right]_{\mathrm{i}}$ in response to high $\mathrm{K}^{+}$ depolarization..$^{42,43}$ Given the less negative resting membrane potential establishment $(-20$ to $-40 \mathrm{mV}$ ) by undifferentiated SH-SY5Y cells ${ }^{12,13,15,45}$ and the difference in VGCC responsiveness found with $50 \mathrm{mM} \mathrm{K}^{+}$depolarization in the present study, we accordingly focused on the L-type calcium channel expression for cells on both flat substrates and in microwell patterns using DM-BODIPY-based immunofluorescence staining.

Figure 5 shows representative fluorescence images for cells on the flat substrate (A) and in the 100-0 (B) and 100 $20 \mu \mathrm{m}(\mathrm{C})$ microwell patterns stained with DM-BODIPY for L-type calcium channels. As can be seen in Figure 5, cells on either the flat substrates or microwell patterns were all positively stained with DM-BODIPY, suggesting uniform expression of L-type calcium channels, which is in agreement with previous findings for this cell line. ${ }^{40-43}$ For a comparison of the expression profiles, percentages of cells with strongly positive expression, as judged by a fluorescence intensity of the seventy-fifth percentile or higher within the percentile frequency distribution, were quantified and compared (Figure 6). To reduce the laser exposure and fluorescence quenching during the capture of confocal images, the quantification was based on low magnification $(20 \times)$ images. Under such conditions, the distinction of N2D and 3D cells was technically difficult and therefore cells inside microwells were collectively referred to as $\mathrm{N} 2 \mathrm{D}+3 \mathrm{D}$ cells. As shown in Figure 6, the percentage of 2D cells (7.8\%) with 

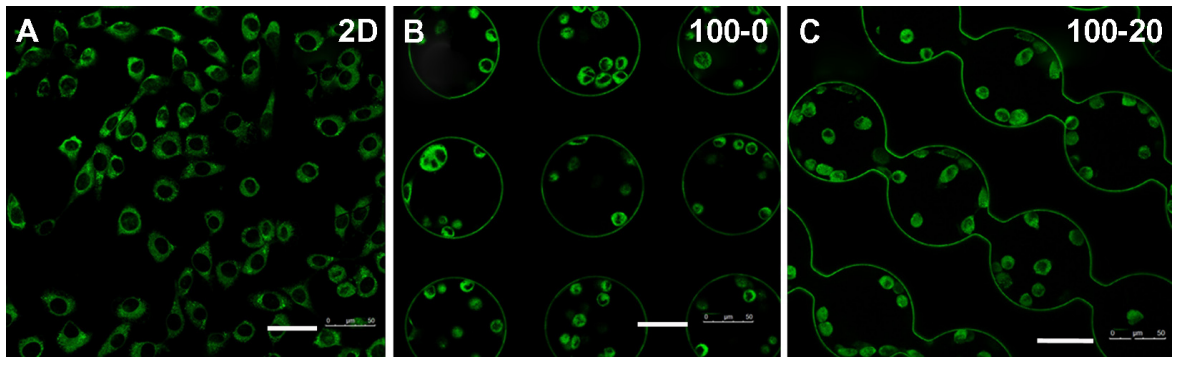

Figure 5 Typical fluorescence images for 2D cells on flat substrates $(\mathbf{A})$, and N2D and 3D cells in the I00-0 $\mu \mathrm{m}(\mathbf{B})$ and I00-20 $\mu \mathrm{m}(\mathbf{C})$ microwell patterns stained with DM-BODIPY for L-type calcium channels.

Notes: The number on each image is microwell diameter-channel width in micrometers. Scale Bar $=100 \mu \mathrm{m}$.

Abbreviations: 2D, two dimensional; N2D, near two dimensional; 3D, three dimensional.

strong L-type channel expression was significantly lower than that of $\mathrm{N} 2 \mathrm{D}+3 \mathrm{D}$ cells on either the $100-0(13.1 \%)$ or the $100-20 \mu \mathrm{m}$ pattern $(15.3 \%)(P<0.05)$. At the same time, $\mathrm{N} 2 \mathrm{D}+3 \mathrm{D}$ cells on the $100-0 \mu \mathrm{m}$ pattern were less positive for L-type channel expression than cells in the 100-20 $\mu \mathrm{m}$ pattern $(P<0.01)$. Taken together, the present results show that cells on the microwell patterns had an L-type channel expression level no less than that of cells on flat substrates, even if the N2D and 3D cells were found to have a lower VGCC responsiveness than 2D cells. These results suggest that the difference in VGCC responsiveness among cells of the 2D, N2D, and 3D growth categories was not attributable to difference in L-type channel expression.

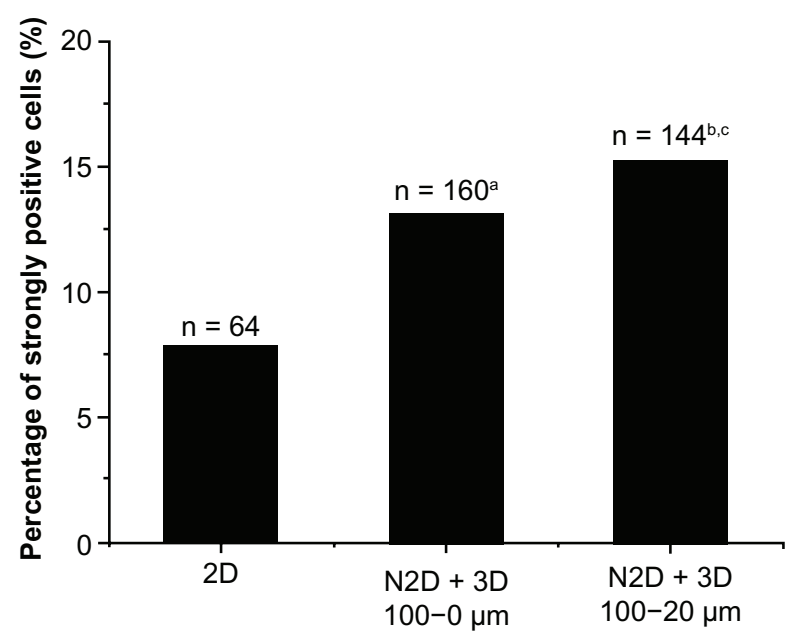

Figure 6 A comparison of percentages of cells with strongly positive L-Type channel expression for cells on flat substrates (2D) and in microwell patterns (N2D + 3D). Notes: Cells were considered to exhibit a strongly positive L-type channel expression when their fluorescence intensity was 75th percentile or higher from the fluorescence frequency distribution. The numbers $100-0 \mu \mathrm{m}$ and $100-20 \mu \mathrm{m}$ are microwell diameter-channel widths in micrometers. Statistically significant difference probability values for comparison with $2 D$ cells on flat substrates: ${ }^{a} P<0.0$ I; ${ }^{b} P<0.0$ I. Statistically significant difference probability values for comparison with N2D+3D cells on the $100-0$ patterns: $c P<0.01$.

Abbreviations: 2D, two dimensional; N2D, near two dimensional; 3D, three dimensional.
There is mounting evidence that suggests a relation between cell morphology and cell function. ${ }^{37,46}$ In recent pioneering work, researchers have even proposed the control of stem cell differentiation through the manipulation of cell spreading or morphology with substrate patterns. ${ }^{47}$ However, few of these studies have ever extended their observation to address a possible correlation between cell spreading and cellular ion channel responsiveness or functionality. Taking the results of cell spreading and cell VGCC responsiveness together, we found that cells inside microwells (N2D or 3D) with smaller projection areas had lower VGCC responsiveness, while cells on flat substrates (2D) with larger projection areas had higher VGCC responsiveness. In addition, for both the two patterns addressed, N2D cells consistently had an intermediate value between $2 \mathrm{D}$ and $3 \mathrm{D}$ cells for either the projection area, the percentage of responding cells, or the response magnitude (Tables 2 and 3). These results suggest that SH-SY5Y cells' VGCC responsiveness might be related to cell spreading, with VGCC responsiveness possibly determined by cell growth characteristics. To conclude a causative relation between cell spreading and VGCC responsiveness may raise concern over the comparison between the 100-0 and $100-20 \mu \mathrm{m}$ pattern or the effects of channel connection in this case, as both $\mathrm{N} 2 \mathrm{D}$ and 3D cells within the wells of the 100-20 $\mu \mathrm{m}$ pattern spread less or had smaller projection areas than their counterparts on the $100-0 \mu \mathrm{m}$ pattern. However, even if the N2D cells in the $100-20 \mu \mathrm{m}$ pattern tended to have a higher percentage of responsive cells, the $3 \mathrm{D}$ cells on the 100-20 $\mu \mathrm{m}$ pattern had a significantly lower responsive cell percentage than their counterparts on the $100-0 \mu \mathrm{m}$ pattern. Besides, we cannot rule out the possibility that there are pattern-linked factors that would have effects on the VGCC responsiveness of the cells. Changes in cell morphology or spreading typically accompany changes in cytoskeleton organization, ${ }^{46,47}$ which may result in changes in ion channel function through linkage to molecular signaling cascades. ${ }^{48}$ 
It is worth noting that our patterns were fabricated with the biodegradable polymer rather than the substrate material used for regular cell culture in a Petri dish. The culture of cells on a biodegradable polymer substrate may cause changes in cell morphology and/or function. ${ }^{17,23}$ Given the fact that the cells were grown on the same polymer material, we believe that the adoption of PLLA for fabricating patterns will not compromise our conclusion on the comparison of projection areas and VGCC responsiveness for cells of the 2D, 3D, and N2D categories. Moreover, the present study of cellular functionality (VGCC responsiveness) in relation to cell morphology or spreading for cells on a biodegradable polymer substrate offers a useful approach for addressing cell-material interactions in research fields of biomaterials and tissue engineering.

Our immunofluorescence results suggest that the difference in VGCC responsiveness found among cells of the 2D, $\mathrm{N} 2 \mathrm{D}$, and 3D growth categories could not be explained by difference in L-type channel expression. To further understand the mechanisms underlying this difference in VGCC responsiveness, it is reasonable to speculate that other types of calcium channels may be involved. In this regard, it would be tempting to evaluate the VGCC responsiveness upon treatment with specific channel blockers to address the contribution of specific calcium channel types. However, the possible interaction among different VGCC types upon blockade with pharmacological blockers, especially when these blockers are combined, ${ }^{40,41}$ will make it difficult to attribute the difference in responsiveness to a specific channel type with this approach when the difference is small, as shown with the 2D, N2D, and 3D growth categories in this study. Thus, more studies are needed.

Further, it is important to note that resting membrane potential establishment affects VGCC functionality and that $3 \mathrm{D}$ cell culture affects the resting membrane potential establishment, ${ }^{12,13,15}$ which in turn is determined by the functional expression of $\mathrm{Na}^{+}$and/or $\mathrm{K}^{+}$channels. Abnormal resting membrane potential establishment has been speculated as one of the important reasons for abnormal VGCC responsiveness. ${ }^{12}$ Moreover, in neuronal cell-based assays with high $\mathrm{K}^{+}$depolarization, the extent of depolarization is usually estimated based on a standard Nernst potassium electrode property (a cell's potassium electrode property describes the dependence of resting membrane potentials on extracellular $\mathrm{K}^{+}$concentration). A standard Nernst potassium electrode property means that the cell's resting membrane potential is exactly the $\mathrm{K}^{+}$equilibrium potential. With an evaluation of the resting membrane potentials in buffers with different concentrations of $\mathrm{K}^{+},{ }^{45}$ it can easily be shown that this is not the case for SH-SY5Y cells. It has been reported that cell VGCC responsiveness could be enhanced through simple manipulation of ion concentration and cell potassium electrode property in a cell-based fluorescence assay. ${ }^{49}$ This raises the possibility that the difference in VGCC responsiveness among 2D, 3D, and N2D cells is a result of difference in resting membrane potential establishment and cell potassium electrode property, which in turn is attributable to the functional expression of $\mathrm{Na}^{+}$and/or $\mathrm{K}^{+}$channels.

Worth further investigation is the physiological or pathophysiological relevance of neuronal culture on microwell patterns with regard to mirroring the in vivo situation in terms of VGCC functionality. To our knowledge, this is the first study to have addressed the functionality of both N2D and 3D cells on the same set of patterns and to confirm the relationship between VGCC responsiveness and cell spreading at three levels of (2D, 3D, and N2D) of cell "spreadness" or roundness. We conclude that N2D cells are not functionally identical to 3D cells under our pattern conditions, at least in terms of VGCC responsiveness. This lower VGCC responsiveness could not be explained by the difference in L-type calcium channel expression. As such, pattern structural dimensions and thus cell growth characteristics and functionality should be carefully evaluated with respect to the in vivo situation if a cell-based assay platform with higher physiological and pathophysiological relevance is expected. Also, an understanding of the relationship between cell growth characteristics on a topographic substrate and the functionality of the target ion channels of the sensor cells offers a feasible approach for manipulation of the channel responsiveness, where a practical need exists. ${ }^{14}$

\section{Conclusion}

We designed and successfully fabricated microwell patterns with PLLA that provided quasi-3D microenvironments for cell interfacing. We achieved the interfacing of SH-SY5Y human neuroblastoma cells with the PLLA microwell patterns and evaluated the growth characteristics of the interfaced cells. Cell growth characteristics were categorized as 2D, 3D, and N2D according to the location of cells within the pattern. Among the nine patterns tested, we found that the $100-0 \mu \mathrm{m}$ and $100-20 \mu \mathrm{m}$ patterns were the most favorable for supporting 3D cell growth. With the two patterns, we further analyzed cell spreading and VGCC responsiveness for the interfaced SH-SY5Y cells in relation to each growth category. We found that cells within the microwells, either $\mathrm{N} 2 \mathrm{D}$ or $3 \mathrm{D}$, were less spread, as exemplified by a more 
rounded shape and less projection areas, than 2D cells on flat PLLA substrates. At the same time, cells in microwells showed a significantly lower VGCC responsiveness than cells on flat substrates. The mechanism for this difference in VGCC functionality was discussed in terms of calcium channel expression and membrane potential establishment. Thus, we have found a correlative relationship between cell spreading and cell VGCC responsiveness. This study indicates that the pattern structure and thus the cell growth characteristics are critical factors in determining cell VGCC responsiveness, and provides an approach for engineering cell functionality in cell-based assay systems and tissue engineering scaffold development.

\section{Acknowledgments}

We acknowledge support from the National Natural Science Foundation of China (30870570), the Foundation for Sci and Tech Research Project of Chongqing (CSTC2009AB5202), the Research Foundation for Doctoral Programs in Universities under the State Ministry of Education of China (No 20100191110032), and the 111 Project of the State Ministry of Education of China (B0623). The authors are indebted to Dr Jinglong Chen in the Division of Molecular Biosciences, The John Curtin School of Medical Research, The Australian National University, Canberra, Australia, for his kind comments and suggestions during the preparation of this manuscript.

\section{Disclosure}

The authors declare no conflicts of interest in this work.

\section{References}

1. Bousse L. Whole cell biosensors. Sens Actuators B Chem. 1996;34(1-3): 270-275.

2. Pancrazio JJ, Whelan JP, Borkholder DA, Ma W, Stenger DA. Development and application of cell-based biosensors. Ann Biomed Eng. 1999;27(6):697-711.

3. Stenger DA, Gross GW, Keefer EW, et al. Detection of physiologically active compounds using cell-based biosensors. Trends Biotechnol. 2001;19(8):304-309.

4. Wang P, Liu Q, editors. Cell-Based Biosensors: Principles and Applications. Norwood, MA: Artech House; 2010.

5. Cukierman E, Pankov R, Yamada KM. Cell interactions with threedimensional matrices. Curr Opin Cell Biol. 2002;14(5):633-639.

6. Mueller-Klieser W. Tumor biology and experimental therapeutics. Crit Rev Oncol Hematol. 2000;36(2-3):123-139.

7. Kunz-Schughart LA, Freyer JP, Hofstaedter F, Ebner R. The use of 3-D cultures for high-throughput screening: the multicellular spheroid model. J Biomol Screen. 2004;9(4):273-285.

8. Jimbo Y, Robinson HP, Kawana A. Simultaneous measurement of intracellular calcium and electrical activity from patterned neural networks in culture. IEEE Trans Biomed Eng. 1993;40(8):804-810.

9. Tatic-Lucic S, Wright JA, Tai YC, Pine J. Silicon cultured-neuron prosthetic devices for in vivo and in vitro studies. Sens Actuators B Chem. 1997;43(1-3):105-109.
10. Leclerc E, Furukawa KS, Miyata F, Sakai Y, Ushida T, Fujii T. Fabrication of microstructures in photosensitive biodegradable polymers for tissue engineering applications. Biomaterials. 2004;25(19): 4683-4690.

11. Wang L, Wu ZZ, Xu BQ, Zhao YP, Kisaalita WS. SU-8 microstructure for quasi-three-dimensional cell-based biosensing. Sens Actuators B Chem. 2009;140(2):349-355.

12. Desai A, Kisaalita WS, Keith C, Wu ZZ. Human neuroblastoma (SHSY5Y) cell culture and differentiation in 3-D collagen hydrogels for cell-based biosensing. Biosens Bioelectron. 2006;21(8):1483-1492.

13. Wu ZZ, Zhao YP, Kisaalita WS. A packed Cytodex microbead array for three-dimensional cell-based biosensing. Biosens Bioelectron. 2006;22(5):685-693.

14. Wu ZZ, Kisaalita WS, Wang L, et al. Effects of topography on the functional development of human neural progenitor cells. Biotechnol Bioeng. 2010;106(4):649-659.

15. Wu ZZ, Zhao Y, Kisaalita WS. Interfacing SH-SY5Y human neuroblastoma cells with SU-8 microstructures. Colloids Surf B Biointerfaces. 2006;52(1):14-21.

16. Nair LS, Laurencin CT. Biodegradable polymers as biomaterials. Prog Polym Sci. 2007;32(8-9):762-798.

17. He L, Liao S, Quan D, et al. The influence of laminin-derived peptides conjugated to Lys-capped PLLA on neonatal mouse cerebellum C17.2 stem cells. Biomaterials. 2009;30(8):1578-1586.

18. Witschi C, Doelker E. Influence of the microencapsulation method and peptide loading on poly(lactic acid) and poly(lactic-co-glycolic acid) degradation during in vitro testing. J Control Release. 1998;51(2-3): 327-341.

19. Rasband WS. ImageJ [computer software]. Bethesda, MD: US National Institutes of Health; 1997-2012. Available from: http://imagej.nih.gov/ ij/. Accessed November 15, 2012.

20. Takahashi A, Camacho P, Lechleiter JD, Herman B. Measurement of intracellular calcium. Physiol Rev. 1999;79(4):1089-1125.

21. Lamb GD, Walsh T. Calcium currents, charge movement and dihydropyridine binding in fast- and slow-twitch muscles of rat and rabbit. J Physiol. 1987;393(1):595-617.

22. Traill KN, Böck G, Winter U, Hilchenbach M, Jürgens G, Wick G. Simple method for comparing large numbers of flow cytometry histograms exemplified by analysis of the CD4 (T4) antigen and LDL receptor on human peripheral blood lymphocytes. $J$ Histochem Cytochem. 1986;34(9):1217-1221.

23. Liu HC, Lee IC, Wang JH, Yang SH, Young TH. Preparation of PLLA membranes with different morphologies for culture of MG-63 Cells. Biomaterials. 2004;25(18):4047-4056.

24. Corey JM, Gertz CC, Wang BS, et al. The design of electrospun PLLA nanofiber scaffolds compatible with serum-free growth of primary motor and sensory neurons. Acta Biomater. 2008;4(4):863-875.

25. Levenberg S, Huang NF, Lavik E, Rogers AB, Itskovitz-Eldor J, Langer R. Differentiation of human embryonic stem cells on threedimensional polymer scaffolds. Proc Natl Acad Sci U S A. 2003; 100(22):12741-12746.

26. Sato T, Chen GP, Ushida T, et al. Evaluation of PLLA-collagen hybrid sponge as a scaffold for cartilage tissue engineering. Mater Sci Eng C Mater Biol Appl. 2004;24(3):365-372.

27. Kato-Negishi M, Tsuda Y, Onoe H, Takeuchi S. A neurospheroid network-stamping method for neural transplantation to the brain. Biomaterials. 2010;31(34):8939-8945.

28. Lv YL, Wu ZZ, Zhang LG, et al. Population expansion of rat hippocampal neural stem cells and their integration with threedimensional microwell patterns. Di 3 Jun Yi Da Xие Xие Bao. 2010; 32(6):520-524. Chinese.

29. Biedler JL, Helson L, Spengler BA. Morphology and growth, tumorigenicity, and cytogenetics of human neuroblastoma cells in continuous culture. Cancer Res. 1973;33(11):2643-2652.

30. Garcia-Gil M, Pesi R, Perna S, et al. 5'-aminoimidazole-4-carboxamide riboside induces apoptosis in human neuroblastoma cells. Neuroscience. $2003 ; 117(4): 811-820$. 
31. Hanada M, Krajewski S, Tanaka S, et al. Regulation of Bcl-2 oncoprotein levels with differentiation of human neuroblastoma cells. Cancer Res. 1993;53(20):4978-4986.

32. Ribas J, Boix J. Cell differentiation, caspase inhibition, and macromolecular synthesis blockage, but not BCL-2 or BCL-XL proteins, protect SH-SY5Y cells from apoptosis triggered by two CDK inhibitory drugs. Exp Cell Res. 2004;295(1):9-24.

33. Wang SS, Good TA. Effect of culture in a rotating wall bioreactor on the physiology of differentiated neuron-like PC12 and SH-SY5Y cells. J Cell Biochem. 2001;83(4):574-584.

34. Martínez E, Engel E, Planell JA, Samitier J. Effects of artificial microand nano-structured surfaces on cell behaviour. Ann Anat. 2009;191(1): 126-135.

35. Griscom L, Degenaar P, LePioufle B, Tamiya E, Fujita H. Cell placement and neural guidance using a three-dimensional microfluidic array. Jpn J Appl Phys. 2001;40(9A):5485-5490.

36. Claverol-Tinturé E, Ghirardi M, Fiumara F, Rosell X, Cabestany J. Multielectrode arrays with elastomeric microstructured overlays for extracellular recordings from patterned neurons. J Neural Eng. 2005; 2(2):L1-L7.

37. Bettinger CJ, Langer R, Borenstein JT. Engineering substrate topography at the micro- and nanoscale to control cell function. Angew Chem Int Ed Engl. 2009;48(30):5406-5415.

38. Guilak F, Cohen DM, Estes BT, Gimble JM, Liedtke W, Chen CS. Control of stem cell fate by physical interactions with the extracellular matrix. Cell Stem Cell. 2009;5(1):17-26.

39. Denyer J, Worley J, Cox B, Allenby G, Banks M. HTS approaches to voltage-gated ion channel drug discovery. Drug Discov Today. 1998; 3(7):323-332.

40. Toselli M, Masetto S, Rossi P, Taglietti V. Characterization of a Voltage-dependent Calcium Current in the Human Neuroblastoma Cell Line SH-SY5Y During Differentiation. Eur J Neurosci. 1991;3(6): 514-522.
41. Reeve HL, Vaughan PF, Peers C. Calcium channel currents in undifferentiated human neuroblastoma (SH-SY5Y) cells: actions and possible interactions of dihydropyridines and omega-conotoxin. Eur J Neurosci. 1994;6(6):943-952.

42. Lambert DG, Whitham EM, Baird JG, Nahorski SR. Different mechanisms of $\mathrm{Ca} 2+$ entry induced by depolarization and muscarinic receptor stimulation in SH-SY5Y human neuroblastoma cells. Brain Res Mol Brain Res. 1990;8(3):263-266.

43. Hettiarachchi NT, Parker A, Dallas ML, et al. alpha-Synuclein modulation of $\mathrm{Ca} 2+$ signaling in human neuroblastoma (SH-SY5Y) cells. J Neurochem. 2009;111(5):1192-1201.

44. Fox AP, Nowycky MC, Tsien RW. Kinetic and pharmacological properties distinguishing three types of calcium currents in chick sensory neurones. J Physiol. 1987;394:149-172.

45. Taglialatela M, Secondo A, Fresi A, et al. Inhibition of depolarizationinduced $[3 \mathrm{H}]$ noradrenaline release from SH-SY5Y human neuroblastoma cells by some second-generation $\mathrm{H}(1)$ receptor antagonists through blockade of store-operated $\mathrm{Ca}(2+)$ channels (SOCs). Biochem Pharmacol. 2001;62(9):1229-1238.

46. Fu JP, Wang YK, Yang MT, et al. Mechanical regulation of cell function with geometrically modulated elastomeric substrates. Nat Methods. 2010;7(9):733-736.

47. Peng R, Yao X, Ding J. Effect of cell anisotropy on differentiation of stem cells on micropatterned surfaces through the controlled single cell adhesion. Biomaterials. 2011;32(32):8048-8057.

48. Walsh KB, Parks GE. Changes in cardiac myocyte morphology alter the properties of voltage-gated ion channels. Cardiovasc Res. 2002;55(1): 64-75.

49. Belardetti F, Tringham E, Eduljee C, et al. A fluorescence-based highthroughput screening assay for the identification of T-type calcium channel blockers. Assay Drug Dev Technol. 2009;7(3):266-280. 


\section{Appendix S I: supplementary methods and results Evaluation of the dynamics for the Calcium Green-I fluorescence response curves}

We have evaluated the VGCC functionality of SH-SY5Y cells, cultured in poly(1-lactic acid) quasi-three-dimensional micropatterns, with respect to fluorescence response magnitudes and percentages of responsive cells upon high $\mathrm{K}$ depolarization. Further evaluation of the fluorescence response curves includes measurement of the dynamic parameters such as rising time (time to peak), falling time (time to return to baseline fluorescence levels), peak duration, and peak area. Similar evaluation of the calcium current dynamics has proved meaningful for analyzing patch clamp recordings. ${ }^{1}$ In a similar manner, measurement of the dynamics for the Calcium Green-1 fluorescence response curves was expected to provide useful information about the calcium signals or VGCC functionality.

The sampling rate of the fluorescence recordings ( 1 frame per 3 seconds) and the fluorescence response are slow in comparison to patch-clamp calcium current signal recordings (tens of seconds vs hundreds of milliseconds). ${ }^{1-3}$ This is mainly due to calcium-induced calcium release and calcium buffering by intracellular calcium stores. ${ }^{4}$ The rising time and falling time of the fluorescence response may be misleading in understanding the VGCC functionality. Because of the overlay of fluorescence quenching on the Calcium Green-1 fluorescence response and the slowness and variability of the descending of the fluorescence responses (especially the final fading) (Figure 3D), the measurements of the peak duration may be technically difficult to interpret. We thus used the peak width at half height (PWHH) as a measure of the duration for the fluorescence response and the peak area (PAR) as another measure for
VGCC responsiveness. However, PAR may be strongly influenced by the fluorescence response duration. PWHHs and PARs were measured with OriginPro software (http:// www.originlab.com/). The half height of a response peak was positioned with the mean of the prestimulus fluorescence intensity value $F_{\text {pre }}$ and peak fluorescence intensity value $F$ (See the Materials and Methods Section). The peak area was measured by calculating the area under the fluorescence response peak and over the average prestimulus baseline $F_{\text {pre }}$. Statistical comparisons of PWHHs and PARs were made with One-way ANOVA.

Table S1 shows the summary of the calculated values of PWHHs and PARs from the fluorescence response curves of 2D SH-SY5Y cells on flat substrates, N2D and 3D cells in microwell patterns. It is evident from the table that $2 \mathrm{D}$ cells on the flat substrates had a PWHH of $28.22 \pm 6.5 \mathrm{~s}$ $(\mathrm{n}=71)$, which was not significantly different from those for N2D and 3D cells in the $100-0 \mu \mathrm{m}$ pattern $(P>0.05)$, but significantly smaller than those for $\mathrm{N} 2 \mathrm{D}$ and $3 \mathrm{D}$ cells in the 100-20 $\mu \mathrm{m}$ pattern $(P<0.05)$. 3D cells in the $100-0 \mu \mathrm{m}$ pattern had a PWHH value larger than that for N2D cells on the same pattern $(P<0.05)$, but this difference was not found for the $100-20 \mu \mathrm{m}$ pattern $(P>0.05)$. Table $\mathrm{S} 1$ also shows that the peak areas for $2 \mathrm{D}$ cells on flat substrates were $319.8 \pm 178.6$ relative fluorescence intensity units (RFIUs) $(n=71)$, which were significantly higher than that for N2D and 3D cells either in the $100-0 \mu \mathrm{m}$ pattern or in the 100-20 $\mu \mathrm{m}$ pattern $(\mathrm{P}<0.05)$. For either of the 2 patterns studied, N2D cells had larger PARs than 3D cells on the same pattern. These results were in agreement with the VGCC response magnitudes and their frequency distribution, as shown in the Results and Discussion Section. The large standard deviations for the PAR values reflected the variations in PWHHs and falling times of the fluorescence responses.

Table SI The peak widths at half height and peak areas for the Calcium Green-I fluorescence response curves from SH-SY5Y cells on flat surfaces and in microwell patterns

\begin{tabular}{|c|c|c|c|c|c|}
\hline & \multirow{2}{*}{$\frac{\text { FS }}{\text { 2D cells }}$} & \multicolumn{2}{|c|}{ Patterns of $100-0 \mu \mathrm{m}$} & \multicolumn{2}{|c|}{ Patterns of $100-20 \mu \mathrm{m}$} \\
\hline & & N2D cells & 3D cells & N2D cells & 3D cells \\
\hline \multirow[t]{2}{*}{ PWHH (s) } & $28.22 \pm 6.5$ & $27.1 \pm 7.6$ & $30.3 \pm 8.9^{d}$ & $31.9 \pm 11.2^{\mathrm{a}, \mathrm{c}}$ & $30.4 \pm 8.1^{\mathrm{a}}$ \\
\hline & $(n=7 I)$ & $(n=62)$ & $(n=48)$ & $(n=65)$ & $(n=89)$ \\
\hline PAR (RFIUs) & $\begin{array}{l}319.8 \pm 178.6 \\
(n=7 I)\end{array}$ & $\begin{array}{l}210 \pm 138.9^{b} \\
(n=62)\end{array}$ & $\begin{array}{l}135.3 \pm 106.7^{\mathrm{b}, \mathrm{e}} \\
(\mathrm{n}=48)\end{array}$ & $\begin{array}{l}251.8 \pm 217.7^{a} \\
(n=65)\end{array}$ & $\begin{array}{l}196.8 \pm 104.3^{\mathrm{b}-\mathrm{d}} \\
(\mathrm{n}=89)\end{array}$ \\
\hline
\end{tabular}

Notes: The numbers 100-0 and 100-20 indicate well diameter-channel width in micrometers for the patterns. Statistically significant difference probability values for comparison with cells on flat substrates: a $P<0.05$; ${ }^{b} P<0.0$ I. Statistically significant difference probability values for comparison with cells on the I00-0 patterns: ${ }^{c} P<0.0$ I. Statistically significant difference probability values for comparison with N2D cells on the same pattern: ${ }^{\mathrm{d} P}<0.05$; ${ }^{\mathrm{e}} P<0.0 \mathrm{I}$.

Abbreviations: FS, flat substrates; PWHH, Peak width at half height; PAR, peak area; 2D, two dimensional; N2D, near two dimensional; 3D, three dimensional; RFIU, relative fluorescence intensity unit; $n$, number of cells. 


\section{References}

1. Toselli M, Masetto S, Rossi P, Taglietti V. Characterization of a Voltagedependent Calcium Current in the Human Neuroblastoma Cell Line SHSY5Y During Differentiation. Eur J Neurosci. 1991;3(6):514-522.

2. Hettiarachchi NT, Parker A, Dallas ML, et al. alpha-Synuclein modulation of $\mathrm{Ca} 2+$ signaling in human neuroblastoma (SH-SY5Y) cells. J Neurochem. 2009;111(5):1192-1201.
3. Vetter I, Lewis RJ. Characterization of endogenous calcium responses in neuronal cell lines. Biochem Pharmacol. 2010;79(6):908-920.

4. Montoya GJ, Sutachan JJ, Corrales A, Xu F, Blanck TJ, RecioPinto E. Pulses of extracellular $\mathrm{K}+$ produce two cytosolic $\mathrm{Ca} 2+$ transients that display different temperature dependence and carbonyl cyanide m-chlorophenyl sensitivity in SH-SY5Y cells. Brain Res. 2008;1213:12-26.

\section{Publish your work in this journal}

The International Journal of Nanomedicine is an international, peerreviewed journal focusing on the application of nanotechnology in diagnostics, therapeutics, and drug delivery systems throughout the biomedical field. This journal is indexed on PubMed Central,

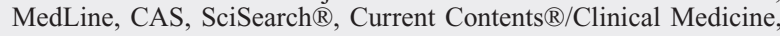

Journal Citation Reports/Science Edition, EMBase, Scopus and the Elsevier Bibliographic databases. The manuscript management system is completely online and includes a very quick and fair peer-review system, which is all easy to use. Visit http://www.dovepress.com/ testimonials.php to read real quotes from published authors.

Submit your manuscript here: http://www.dovepress.com/international-journal-of-nanomedicine-journal 